\title{
Report of the American College of Cardiology (ACC) Scientific Sessions 2016, Chicago
}

\author{
Toshiaki Mano, MD, PhD; Kazuhiro Yamamoto, MD, PhD
}

\begin{abstract}
The $65^{\text {th }}$ Annual Scientific Sessions of the American College of Cardiology (ACC) were held at McCormick Place, Chicago, from April 2-4, 2016. The ACC Scientific Sessions are one of the 2 major scientific cardiology meetings in the USA and one of the major scientific meetings of cardiology in the world. It had an attendance of 18,769 and over 2,000 oral and poster abstracts, including 8 late-breaking clinical trials. This report presents the key presentations and the highlights from the ACC Scientific Sessions 2016 in Chicago. (Circ J 2016; 80: 1308-1313)
\end{abstract}

Key Words: American College of Cardiology; Late-breaking clinical trials; Scientific Sessions

$\mathbf{T}$ he $65^{\text {th }}$ Annual Scientific Sessions and Expo of the American College of Cardiology (ACC.16) were held at McCormick Place Chicago from April 2-4, 2016 (Figure 1). The 64 ${ }^{\text {th }}$ Annual Sessions were held in San Diego in $2015^{1}$ and the $63^{\text {th }}$ Sessions in Washington DC in $2014 .^{2}$ The ACC Scientific Sessions are one of the 2 major scientific cardiology meetings in the USA, as well as the American Heart Association Scientific Meeting, ${ }^{3}$ and one of the major scientific meetings of cardiology in the world as well as the European Society of Cardiology Congress. ${ }^{4}$ The total attendance at ACC.16 was 18,769. There were over 2,000 oral and poster abstracts, including 8 late-breaking clinical trials (LBCTs). This report presents the key presentations and the highlights from the ACC Scientific Sessions 2016 in Chicago.

\section{Opening Showcase}

The ACC Scientific Sessions started with singing of the national anthem. Next, the First Lady Michelle Obama sent a video message, which highlighted the "Let's Move" campaign, and she thanked the ACC and attendees for focusing on lifestyle changes that can prevent cardiovascular (CV) disease.

As the opening showcase of the Sessions, ACC President Kim Allan Williams welcomed CV professionals to Chicago (Figure 2). Williams gave his presidential address, highlighting that $\mathrm{CV}$ disease continues to be the number 1 cause of death around the world despite significant recent gains in reducing $\mathrm{CV}$ mortality and preventing and treating the disease. He stated "We must own our actions and we must be visible to the public and our patients in positive ways that affect their lives."

David Nash provided the $23^{\text {rd }}$ Simon Dack Lecture, which focused on "Population Health: Is it the Secret Sauce?" (Figure 2). Nash highlighted the challenges in current health care, including confusion by patients around treatment, the need for better evidence at bedside, the current balancing act between free-for-service compensation and value-based payments. He cited approximately $40 \%$ of people who are at risk of heart disease as a result of smoking, unhealthy eating, lack of exercise and/or alcohol consumption. He applauded the ACC's attempt at recognizing these challenges and stressed the need for aligning physician and executive compensation with population health management.

\section{LBCTs}

There were 8 LBCT sessions in ACC.16, including the joint ACC/JACC, the joint ACC/Journal of the American Medical Association, the joint ACC/TCT and the joint ACC/New England Journal of Medicine.

\section{PARTNER 2A}

Craig Smith reported the final results from the randomized placement of aortic transcatheter valves 2 study (PARTNER 2A), which compared transcatheter aortic valve replacement (TAVR) with surgery in intermediate-risk patients with aortic stenosis (AS). Previous trials have shown that survival rates are similar with TAVR and surgical AVR for high-risk AS patients. ${ }^{5,6}$ In this randomized trial, the investigators evaluated 2,032 AS patients with intermediate risk from 57 centers, assigned to receive either TAVR or surgical AVR. The primary endpoint was death from any cause or disabling stroke at 2 years. Patients were divided into 2 cohorts: $76.3 \%$ in the transfemoral-access cohort and $23.7 \%$ in the transthoracicaccess cohort. The primary endpoint was similar in the TAVR and surgery groups $(\mathrm{P}=0.001$ for non-inferiority). At 2 years, event rates were $19.3 \%$ in the TAVR group and $21.1 \%$ in the surgery group (hazard ratio [HR] in the TAVR group, 0.89;

The opinions expressed in this article are not necessarily those of the editors or of the Japanese Circulation Society.

Received April 14, 2016; accepted April 19, 2016; released online May 6, 2016

Cardiovascular Division, Department of Internal Medicine, Hyogo College of Medicine, Nishinomiya (T.M.); Division of Cardiovascular Medicine, Endocrinology and Metabolism, Faculty of Medicine, Tottori University, Yonago (K.Y.), Japan

Mailing address: Toshiaki Mano, MD, PhD, Cardiovascular Division, Department of Internal Medicine, Hyogo College of Medicine, 1-1

Mukogawa-cho, Nishinomiya 663-8501, Japan. E-mail: mano@hyo-med.ac.jp

ISSN-1346-9843 doi:10.1253/circj.CJ-16-0368

All rights are reserved to the Japanese Circulation Society. For permissions, please e-mail: cj@j-circ.or.jp 

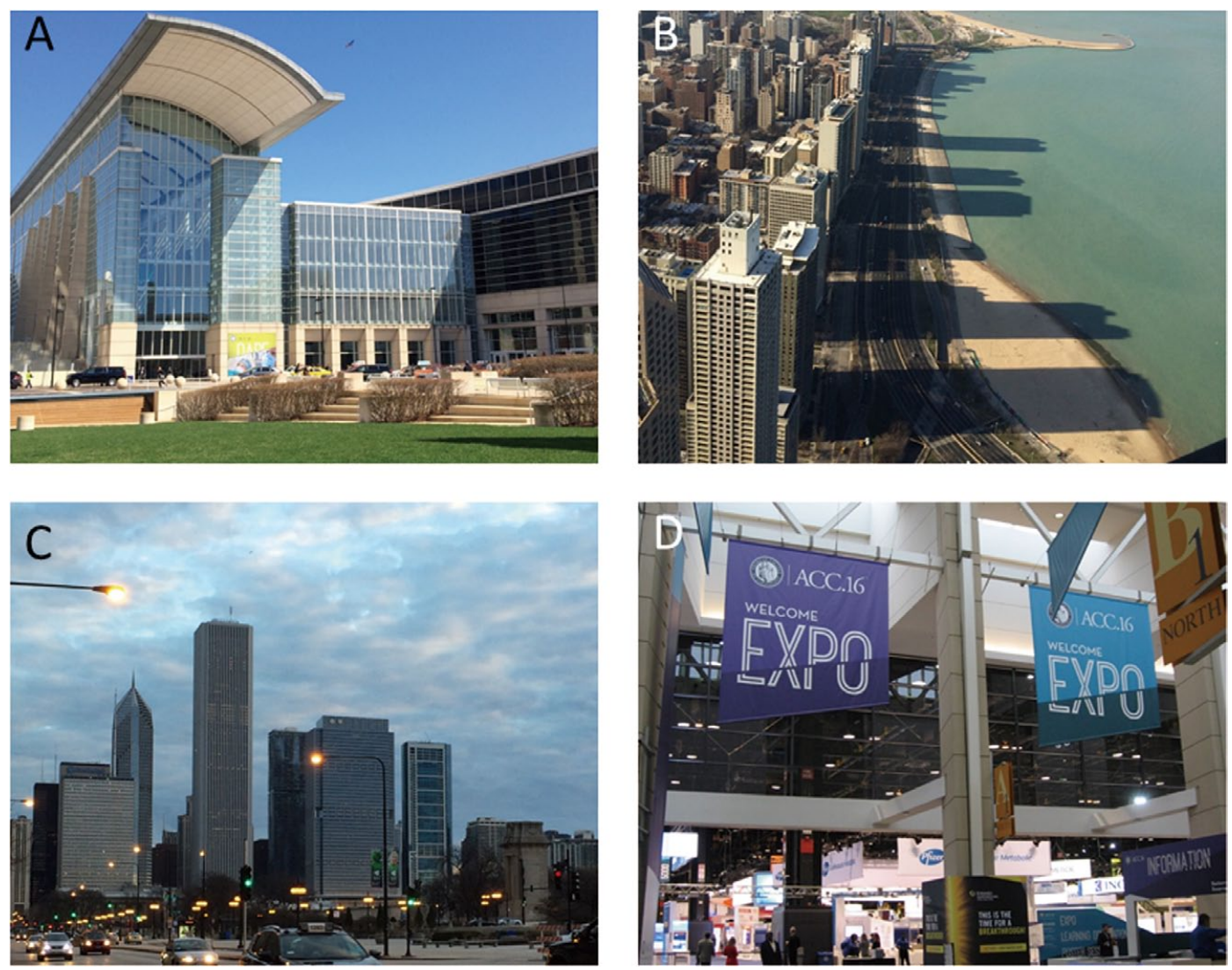

Figure 1. The American College of Cardiology Scientific Sessions and EXPO 2016 were held from April 2-4, 2016 at (A) McCormick Place, Chicago. (B,C) The variable weather in Chicago: bright sunny days or chilly with intermittent snow showers. (D) The ACC.16 Expo was held together with the Scientific Sessions, bringing together more than 275 exhibiting companies and organizations showcasing the latest advances in the field.

$95 \%$ confidence interval $(\mathrm{CI}), 0.73-1.09, \mathrm{P}=0.25)$. TAVR showed less primary events than surgery in the transfemoralaccess cohort (HR, 0.79; 95\% CI, 0.62-1.00; $\mathrm{P}=0.05)$, whereas the primary outcomes in both cohorts were similar in the transthoracic-access group. As for the secondary endpoints, the TAVR group showed attainment of larger aortic valve area than the surgical group and lower rates of acute kidney injury, severe bleeding, and new-onset atrial fibrillation (AF) but the surgery group showed fewer major vascular complications and less paravalvular aortic regurgitation. The presenter concluded that TAVR and surgical AVR were similar in terms of the primary endpoint of death or disabling stroke in intermediate-risk patients. ${ }^{7}$

\section{HOPE-3 Trial}

In the HOPE-3 trial, 12,705 participants at intermediate risk without $\mathrm{CV}$ diseases were assigned into $2 \times 2$ cohorts: rosuvastatin $(10 \mathrm{mg} /$ day $)$ or placebo, candesartan $(16 \mathrm{mg} /$ day $)$ plus hydrocholorothiazide $(12.5 \mathrm{mg} /$ day $)$ or placebo. This trial had 3 parts and the results were presented separately in the sessions and surprisingly were also published as 3 independent papers. ${ }^{8-10}$

Eva Lonn presented that only blood pressure-lowering therapy showed no significant improvements overall in the cohort compared with placebo in people at moderate risk. In patients with BP $>143.5 \mathrm{mmHg}$ prior to therapy, $4.8 \%$ of patients received $\mathrm{BP}$-lowering therapy experienced the first co-primary endpoint and $5.7 \%$ experienced the second co-primary endpoint, which was significantly lower than in patients receiving placebo $(6.5 \%$ and $7.5 \%$, respectively).

Jackie Bosch focused on the effects of rosuvastatin on primary prevention of $\mathrm{CV}$ disease in diverse ethnic groups with moderate risk. This analysis aimed to clarify whether the benefits of statins can be extended to an intermediate-risk, ethnically diverse population without $\mathrm{CV}$ disease, because the previous trials involved mainly white participants with elevated lipid levels or inflammatory markers. The mean lowdensity lipoprotein (LDL) level was $26.5 \%$ lower in the rosuvastatin group than in the placebo group. The first coprimary events occurred in $3.7 \%$ of the rosuvastatin group and in $4.8 \%$ of the placebo group $(\mathrm{P}=0.002)$ and the second coprimary events occurred in $4.4 \%$ of the rosuvastatin group and in $5.7 \%$ of the placebo group $(\mathrm{P}<0.001)$. Those results were consistent in subgroups divided by $\mathrm{CV}$ risk at baseline, lipid level, C-reactive protein level, BP, and race or ethnic origin. In the rosuvastatin group, there was no excess of diabetes or cancers, but there were more cataract surgeries and muscle symptoms than in the placebo group $(\mathrm{P}=0.005)$. They concluded that rosuvastatin treatment resulted in a lower risk of $\mathrm{CV}$ events than placebo in an intermediate-risk, ethnically 

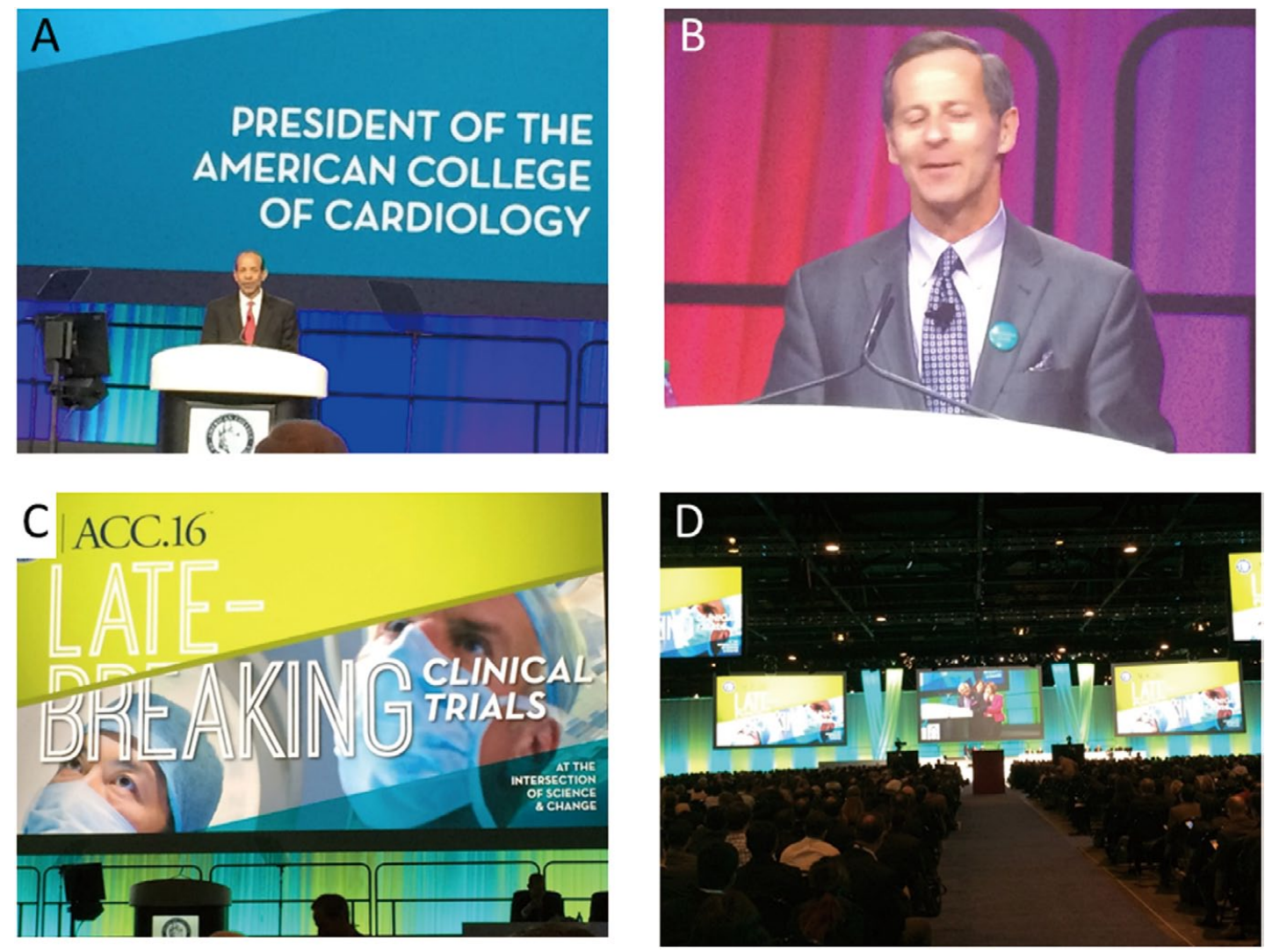

Figure 2. Snapshots from ACC.16. (A) ACC president Kim Allan Williams presenting his Opening Remarks. (B) David Nash gave the $23^{\text {rd }}$ Simon Dack Lecture. (C,D) The scientists presented the late-breaking clinical trials sessions to a capacity audience.

diverse population without $\mathrm{CV}$ diseases.

Salim Yusuf presented the results of combination therapy. They compared 3,180 participants assigned to combination therapy, rosuvastatin and the 2 antihypertensive drugs, with 3,168 assigned to dual placebo. Reduction in LDL level was $33.7 \mathrm{mg} / \mathrm{dl}$ greater in the combination group than in the placebo group. Decrease in BP was $6.2 \mathrm{mmHg}$ greater in the combination group than in the placebo group. Both the first and second co-primary outcome occurred at lower rates in the combination group than in the placebo group $(\mathrm{P}=0.005, \mathrm{P}=0.003$, respectively). In the combination group, muscle weakness and dizziness occurred more. They concluded that the combination of rosuvastatin, candesartan, and hydrochlorothiazide was associated with a lower rate of $\mathrm{CV}$ events than placebo in people with intermediate risk who did not have CV diseases.

\section{ACCELERATE Trial}

Stephen Nicholls presented the effect of the cholesteryl ester transfer protein inhibitor, evacetrapib, on $\mathrm{CV}$ events as the results of the ACCELERATE trial. ${ }^{11}$ The 12,092 patients at high vascular risk defined as ACS within 30-365 days, diabetes with coronary disease, peripheral arterial disease or cerebrovascular disease were enrolled. They were randomized into patients given evacetrapib at $130 \mathrm{mg}$ and patients given placebo. A minimum of 700 patients had hard events (CV death, myocardial infarction or stroke) and the minimum follow-up period was 1.5 years. The study terminated prematurely on the recommendation of the Data Monitoring Committee for clinical futility for the primary composite endpoint. Nicholls presented the result of the preliminary analysis after $98.8 \%$ of patients completed their end-of-study visit, prior to final database lock. Mean high-density lipoprotein cholesterol levels increased to $104 \mathrm{mg} / \mathrm{dl}$ in the evacetrapib group (130\% increase compared with $46 \mathrm{mg} / \mathrm{dl}$ in the placebo group) and LDL cholesterol reduced to $55 \mathrm{mg} / \mathrm{dl}$ in the evacetrapib group $(37 \%$ decrease compared with $84 \mathrm{mg} / \mathrm{dl}$ in the placebo group). The cumulative incidence of the primary endpoint was similar in both groups $(\mathrm{P}=0.85)$. There were no differences between groups for the secondary efficacy endpoints.

\section{GAUSS-3}

Steven Nissen presented the results from the GAUSS-3 trial, which compared the PCSK9 inhibitor evolocumab with ezetimibe in statin-intolerant patients. This study aimed to identify patients with muscle symptoms confirmed by statin re-challenge approach and compare lipid-lowering efficacy for 2 non-statin therapies, ezetimibe and evolocumab. A total of 511 adult patients with a history of intolerance to statins were enrolled. After randomization into the atorvastatin or placebo group, participants were re-randomized to evolocumab or ezetimibe. Muscle symptoms occurred in $42.6 \%$ of atorvastatin-treated patients. Mean \% change in LDL level was $-16.7 \%$ in the ezetimibe group and $-54.5 \%$ in the evolocumab group. Muscle symptoms were reported in $28.8 \%$ of the ezetimibe 
group and $20.7 \%$ of the evolocumab group, while the discontinuation rate was $6.8 \%$ of the ezetimibe group and $0.7 \%$ of the evolocumab group. They concluded that for patients with statin intolerance related to muscle-related adverse effects, the use of evolocumab resulted in a greater reduction in LDL level than ezetimibe. ${ }^{12}$

\section{LDL-C, Familial Hypercholesterolemia (FH) Mutations Status and Risk for Coronary Artery Disease (CAD)}

Amit Khera reported the results of a study entitled LDL cholesterol, FH mutation status and risk for CAD. Only $2 \%$ of the subjects with LDL $>190 \mathrm{mg} / \mathrm{dl}$ had a FH mutation; the remainder was likely related to polygenic or environment causes in terms of diagnostic yield. For any given LDL, the risk of CAD was substantially higher among those with a FH mutation, likely because of increased lifelong exposure to circulating LDL. ${ }^{13}$

\section{The Stepathlon CV Health Study}

Anand Ganesan reported the findings of the Stepathlon study, which tested an effective way to motivate patients' competitive spirit to increase exercise and lose weight. Study data were prospectively collected electronically via questionnaires. The authors repeated the study 3 times and got the same results each time: improved step count, increased exercise days, decreased sitting duration and weight reduction. Moreover, the improvements were observed in both men and women, in all geographic regions. They emphasized that this is a low-cost intervention that can address entire populations. ${ }^{14}$

\section{DANAMI 3-Defer}

Henning Kelbaek presented the results of DANAMI 3-DEFER, designed to compare the utility of deferred vs. immediate percutaneous coronary intervention (PCI) in patients presenting with ST-elevation myocardial infarction (STEMI) and referred for primary PCI. A total of 1,215 STEMI patients in whom the operators could establish Thrombolysis in Myocardial Infarction (TIMI) 2-3 flow without stenting and with minimal acute manipulation or patients presenting with TIMI 2-3 flow were randomized to stent implantation after $48 \mathrm{~h}$ or immediate stenting. The primary outcome for deferred vs. immediate stenting had a HR of 0.99 , (95\% CI $0.75-1.29$, $\mathrm{P}=0.92)$. These results indicated that deferred stenting at the time of primary PCI in STEMI patients is not superior for adverse CV outcomes compared with immediate stenting, which is conventional practice. ${ }^{15}$

\section{EARLY-BAMI}

Vincent Roolvink presented the results of the EARLY-BAMI trial to assess the safety and efficacy of early administration of intravenous (IV) metoprolol in patients presenting with STEMI and scheduled for primary PCI. A total of 683 patients were randomized to receive IV bolus of $5 \mathrm{mg}$ metoprolol or placebo. The primary endpoint for the metoprolol group vs. placebo group was $15.3 \%$ vs. $14.9 \%(\mathrm{P}=0.61)$. This trial showed that early routine administration of IV metoprolol is not beneficial in reducing infarct size in patients with STEMI and primary PCI. ${ }^{16}$

\section{The Resuscitation Outcomes Consortium Amiodarone, Lidocaine, Placebo Study}

Antiarrhythmic drugs are usually used in out-of-hospital cardiac arrest (OHCA) with shock-refractory ventricular fibrillation (VF) or pulseless ventricular tachycardia (VT), although the benefits for survival of these therapies have not been established. Peter Kudenchuk reported the results of the ALPS study. In this randomized and double-blind trial, adult patients with OHCA and shock-refractory VF or pulseless VT were assigned to an amiodarone, lidocaine or saline group. This study suggested that there were no significant differences in survival to hospital discharge or survival with favorable neurological outcomes among these 3 groups. ${ }^{17}$

\section{FIRE AND ICE}

Karl-Heinz Kuck reported the results of a multicenter, randomized trial to determine whether cryoballoon ablation was non-inferior to radiofrequency (RF) ablation in symptomatic patients with drug-refractory paroxysmal AF (FIRE AND ICE). A total of 762 patients were randomized to cryoballoon ablation or RF ablation. The primary efficacy endpoint occurred in $34.6 \%$ of the cryoballoon patients and $35.9 \%$ of the RF patients (HR, 0.96; 95\% CI, 0.76-1.22; P<0.001 for noninferiority). The primary safety endpoint occurred similarly in both groups $(\mathrm{P}=0.24)$. The authors concluded that cryoballoon ablation was non-inferior to RF ablation with respect to efficacy for the treatment of patients with drug-refractory paroxysmal AF, and there were no differences between the 2 methods with regard to overall safety. ${ }^{18}$

\section{Randomized Trial of Rate Control vs. Rhythm Control for AF After Cardiac Surgery}

Marc Gillinov presented the results of a randomized trial to determine the efficacy and safety of a rate control strategy using $\beta$-blocker, calcium-channel blocker, or digoxin vs. a rhythm control strategy using amiodarone and/or DC cardioversion for postoperative AF in patients undergoing cardiac surgery. Patients with postoperative AF were randomized to either rhythm or rate control strategy. Primary outcome for rate vs. rhythm control was $5.1 \%$ vs. $5.0 \%(\mathrm{P}=0.76)$. There were no significant differences in the secondary outcomes in both groups. Those results suggested that a rate control strategy is similar in efficacy to a rhythm control strategy for postoperative AF in patients undergoing cardiac surgery. ${ }^{19}$

\section{LATTITUDE-TIMI 60}

Michelle O'Donoghue reported the results of the LATITUDETIMI 60 trial to compare the efficacy of losmapimod, a selective and reversible inhibitor of P38 MAP kinase, on CV outcomes in patients hospitalized with acute myocardial infarction (AMI). A total of 3,503 patients hospitalized with AMI on guideline-recommended therapy were randomized to either losmapimod $7.5 \mathrm{mg}$ or placebo. The trial was designed in 2 phases: phase A for initial safety and exploratory efficacy and a larger phase B if phase A was positive, but the trial was terminated after phase A because of futility. The primary outcome for losmapimod vs. placebo was $8.1 \%$ vs. $7.0 \%(\mathrm{P}=0.24)$. P38 inhibition was postulated to have salutary effects in AMI patients by reducing inflammation, but losmapimod was not superior in reducing CV events at 12 weeks in patients hospitalized with an AMI despite effects to reduce hs-CRP levels. ${ }^{20}$

\section{ATMOSPHERE}

$\mathrm{J}$ McMurray reported the results of the ATMOSPHERE trial to compare the ACE inhibitor enalapril with the renin inhibitor aliskiren to test superiority or at least non-inferiority and with the combination of the 2 treatments to test superiority in patients with heart failure $(\mathrm{HF})$ and reduced ejection fraction. This study assigned 7,016 patients to receive enalapril at a dose of 5 or $10 \mathrm{mg}$, receive aliskiren at a dose of $300 \mathrm{mg}$ or to receive both treatments. The primary composite outcome was 

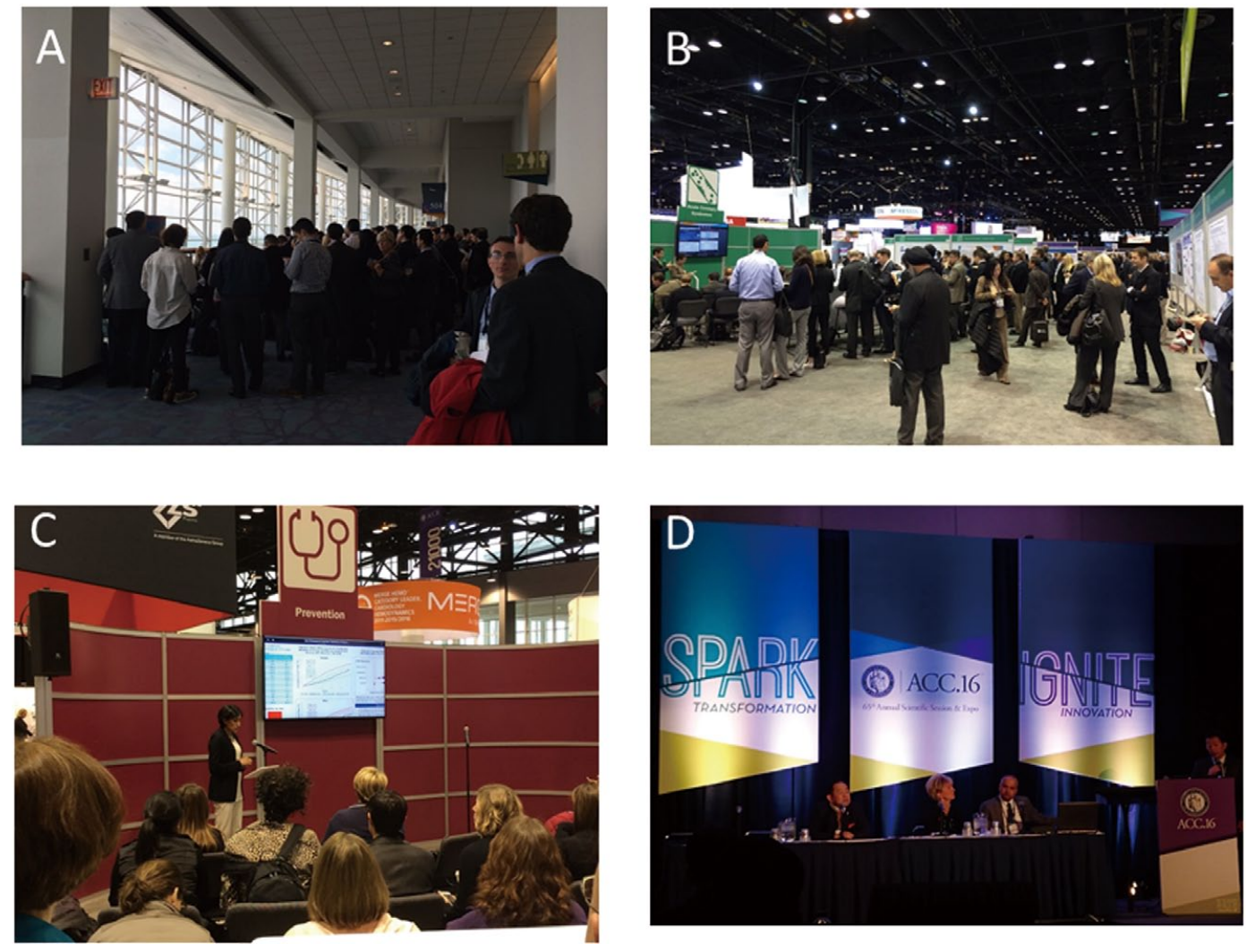

Figure 3. Snapshots from ACC.16. (A) Those who could not get into the room watched monitors outside the hall. (B) Many scientific issues were discussed at poster presentations. (C) Moderated poster session regarding prevention of cardiovascular disease, the main target of ACC.16. (D) The international session joining the British Cardiovascular Society, Japanese College of Cardiology and ACC entitled "Cardiomyopathy, Diabetes and Heart Failure".

$32.9 \%$ in the combination-therapy group, $34.6 \%$ in the enalapril group and $33.8 \%$ in the aliskiren group after a median follow-up of 36.6 months. There was a higher risk of hypotensive symptoms, elevated serum creatinine level and elevated potassium level in the combination-therapy group than in the enalapril group. The authors concluded that in patients with $\mathrm{HF}$, the addition of aliskiren to enalapril led to more adverse events without an increase in benefit and non-inferiority was not shown for aliskiren as compared with enalapril. ${ }^{21}$

\section{IxCell-DCM}

Timothy Henry presented the results of a clinical trial of cell therapy in patients with ischemic HF to test the safety and efficacy of catheter-based transendocardial injection of ixmyelocel-T cell therapy in patients with $\mathrm{HF}$ and reduced ejection fraction. In this randomized, double-blind, placebo-controlled phase $2 \mathrm{~B}$ trial, patients with NYHA III or IV symptomatic HF caused by ischemic dilated cardiomyopathy were assigned to receive ixmyelocel-T or placebo at the time of bone marrow aspiration and followed for 12 months. The primary endpoint was observed in $38 \%$ of the ixmyelocel-T group and $49 \%$ of placebo group (risk ratio, 0.63; 95\% CI, 0.42-0.97; $\mathrm{P}=0.0344$ ). This result indicated that the transendocardial delivery of ixmyelocel-T resulted in a significant reduction in clinical cardiac events.

\section{INOVATE-HF}

Michael Gold presented the results of a trial to evaluate vagus nerve stimulation vs. optimal medical therapy among patients with stable HF. The 707 eligible patients were randomized to device implant, which provided vagus nerve stimulation, or optimal medical therapy. The trial was terminated early for futility for the primary outcome. The primary outcome occurred similarly in $30.3 \%$ of the vagus nerve stimulation group vs. $25.8 \%$ of the control group $(\mathrm{P}=0.37)$. However, the secondary outcomes, quality of life, NYHA class and 6-min walking distance were favorably affected by vagus nerve stimulation $(\mathrm{P}<0.05)$ without the differences in LV stroke volume index. This INOVATE-HF trial failed to show that vagus nerve stimulation improved clinical outcomes vs. optimal therapy.

\section{IMPEDANCE-HF}

Michael Shochat reported the results of the IMPEDANCE-HF trial to evaluate the efficacy of lung impedance-guided treatment in reducing congestive $\mathrm{HF}(\mathrm{CHF})$ hospitalization. A total of 256 patients with $\mathrm{CHF}$ with reduced ejection fraction were randomized to either noninvasive lung impedance-guided management or routine management. The primary outcome for lung impedance-guided arm vs. routine management was 0.52 vs. 1.23 per patient-year $(\mathrm{P}<0.001)$. As the secondary outcomes, a significant reduction was noted in all-cause and cardiac mortality with lung impedance-guidance $(\mathrm{P}<0.001$ for 
both). These results indicated that noninvasive lung impedance-guided management is superior to routine management in reducing CHF hospitalizations at 1 year and beyond. ${ }^{22}$

\section{Special Lectures}

Carole Warnes conducted the $47^{\text {th }}$ Annual Louis F. Bishop lecture entitled "Adult Congenital Heart Disease (ACHD): The Challenges of a Lifetime." This lecture highlighted the challenges faced by surgeons, cardiologists and ACHD patients, and the need for advanced education and training resources for all these groups.

\section{Closing Remarks}

The ACC Scientific Sessions have grown to become one of the largest cardiology meetings in the world. The ACC Sessions mainly offer clinical scientific evidence and are attractive for cardiologists, CV surgeons and other healthcare professionals. For Japanese clinicians and scientists, the ACC Sessions provide much important information, including the latest clinical evidence (Figure 3).

We hope this report gives the latest knowledge in clinical cardiology although it is a brief summary.

\section{Disclosures}

K.Y. is a fellow of the ACC. T.M. has no other conflict of interest to disclose regarding the contents.

\section{References}

1. Murohara T. Report of the American College of Cardiology (ACC) scientific sessions 2015, San Diego. Circ J 2015; 79: 1193-1198.

2. Kusunose K. Report of the American College of Cardiology (ACC) scientific sessions 2014, Washington, DC. Circ J 2014; 78: 1311 1316.

3. Kohno T. Report of the American Heart Association (AHA) scientific sessions 2014, Chicago. Circ J 2015; 79: 34-40.

4. Muramatsu T, Ozaki Y. European Society of Cardiology (ESC) congress report from Barcelona 2014. Circ J 2014; 78: 2610-2618.

5. Kapadia SR, Leon MB, Makkar RR, Tuzcu EM, Svensson LG, Kodali S, et al. 5-year outcomes of transcatheter aortic valve replacement compared with standard treatment for patients with inoperable aortic stenosis (PARTNER 1): A randomised controlled trial. Lancet 2015; 385: 2485-2491.

6. Mack MJ, Leon MB, Smith CR, Miller DC, Moses JW, Tuzcu EM, et al. 5-year outcomes of transcatheter aortic valve replacement or surgical aortic valve replacement for high surgical risk patients with aortic stenosis (PARTNER 1): A randomised controlled trial. Lancet 2015; 385: 2477-2484.

7. Leon MB, Smith CR, Mack MJ, Makkar RR, Svensson LG, Kodali SK, et al. Transcatheter or surgical aortic-valve replacement in intermediate-risk patients. $N$ Engl J Med 2016; 374: 1609-1620.

8. Lonn EM, Bosch J, Lopez-Jaramillo P, Zhu J, Liu L, Pais P, et al.
Blood-pressure lowering in intermediate-risk persons without cardiovascular disease. $N$ Engl J Med 2016 April 2, doi:10.1056/ NEJMoa1600175.

9. Yusuf S, Bosch J, Dagenais G, Zhu J, Xavier D, Liu L, et al. Cholesterol lowering in intermediate-risk persons without cardiovascular disease. N Engl J Med 2016 April 2, doi:10.1056/NEJMoa1600176.

10. Yusuf S, Lonn E, Pais P, Bosch J, Lopez-Jaramillo P, Zhu J, et al. Blood-pressure and cholesterol lowering in persons without cardiovascular disease. $N$ Engl J Med 2016 April 2, doi:10.1056/ NEJMoa1600177.

11. Nicholls SJ, Lincoff AM, Barter PJ, Brewer HB, Fox KA, Gibson $\mathrm{CM}$, et al. Assessment of the clinical effects of cholesteryl ester transfer protein inhibition with evacetrapib in patients at high-risk for vascular outcomes: Rationale and design of the ACCELERATE trial. Am Heart J 2015; 170: 1061 - 1069.

12. Nissen SE, Stroes E, Dent-Acosta RE, Rosenson RS, Lehman SJ, Sattar N, et al. Efficacy and tolerability of evolocumab vs ezetimibe in patients with muscle-related statin intolerance: The GAUSS-3 randomized clinical trial. JAMA 2016; 315: 1580-1590.

13. Khera AV, Won HH, Peloso GM, Lawson KS, Bartz TM, Deng X, et al. Diagnostic yield of sequencing familial hypercholesterolemia genes in patients with severe hypercholesterolemia. J Am Coll Cardiol 2016 March 28, doi:10.1016/j.jacc.2016.03.520.

14. Ganesan AN, Louise J, Horsfall M, Bilsborough SA, Hendriks J, McGavigan AD, et al. International mobile-health intervention on physical activity, sitting, and weight: The Stepathlon Cardiovascular Health Study. J Am Coll Cardiol 2016 March 15, doi:10.1016/j. jacc.2016.03.472.

15. Kelbaek H, Hofsten DE, Kober L, Helqvist S, Klovgaard L, Holmvang L, et al. Deferred versus conventional stent implantation in patients with ST-segment elevation myocardial infarction (DANAMI 3-DEFER): An open-label, randomised controlled trial. Lancet 2016 April 1, doi:10.1016/S0140-6736(16)30072-1.

16. Roolvink V, Ibanez B, Ottervanger JP, Pizarro G, van Royen N, Mateos A, et al. Early administration of intravenous beta blockers in patients with ST-elevation myocardial infarction before primary PCI. J Am Coll Cardiol 2016 March 29, doi:10.1016/j.jacc.2016.03.522.

17. Kudenchuk PJ, Brown SP, Daya M, Rea T, Nichol G, Morrison LJ, et al. Amiodarone, lidocaine, or placebo in out-of-hospital cardiac arrest. N Engl J Med 2016; 374: 1711-1722.

18. Kuck KH, Brugada J, Furnkranz A, Metzner A, Ouyang F, Chun KR, et al. Cryoballoon or radiofrequency ablation for paroxysmal atrial fibrillation. $N$ Engl J Med 2016 April 4, doi:10.1056/ NEJMoa1602014.

19. Gillinov AM, Bagiella E, Moskowitz AJ, Raiten JM, Groh MA, Bowdish ME, et al. Rate control versus rhythm control for atrial fibrillation after cardiac surgery. N Engl J Med 2016 April 4, doi:10.1056/NEJMoa1602002.

20. O'Donoghue ML, Glaser R, Cavender MA, Aylward PE, Bonaca MP, Budaj A, et al. Effect of losmapimod on cardiovascular outcomes in patients hospitalized with acute myocardial infarction: A randomized clinical trial. JAMA 2016; 315: 1591-1599.

21. McMurray JJ, Krum H, Abraham WT, Dickstein K, Kober LV, Desai AS, et al. Aliskiren, enalapril, or aliskiren and enalapril in heart failure. N Engl J Med 2016; 374: 1521-1532.

22. Shochat MK, Shotan A, Blondheim DS, Kazatsker M, Dahan I, Asif A, et al. Non-invasive lung IMPEDANCE-guided preemptive treatment in chronic heart failure patients: A randomized controlled trial (IMPEDANCE-HF Trial). J Card Fail 2016 March 31, doi:10.1016/j. cardfail.2016.03.015. 